\title{
İlköğretimde Okuyan Öğrencilerin Ailelerinin Diş Sağlığına Yönelik Bilgi Düzeylerinin Değerlendirilmesi: Pilot Çalışma
}

\author{
Evaluation of the Knowledge Levels of Dental Health of Parents of Primary School \\ Students: Pilot Study
}

\author{
Gülsüm Kaya ${ }^{1}$, Rasime Öznur Halıcı ${ }^{2}$ Arzu Kayın², Metin Çoban², Şeyma Trabzon³, \\ Merve Köseoğlu ${ }^{4}$, Selma Altındiş ${ }^{5}$ \\ ${ }^{1}$ Sakarya Üniversitesi Eğitim ve Araştırma Hastanesi, Enfeksiyon Kontrol Komitesi, Sakarya, Türkiye \\ ${ }^{2}$ Sakarya Ağız ve Diş Sağ̆lğ̆ Hastanesi, Sakarya, Türkiye \\ ${ }^{3}$ Sakarya üniversitesi, Sağlık Hizmetleri Meslek Yüksek Okulu, Sakarya, Türkiye \\ ${ }^{4}$ Sakarya Üniversitesi, Diş Hekimliği Fakültesi, Protez AD, Sakarya, Türkiye \\ ${ }^{5}$ Sakarya Üniversitesi, İsletme Fakültesi, Sağlık yönetimi AD, Sakarya, Türkiye
}

ORCID

Gülsüm Kaya: https://orcid.org/0000-0003-2517-5512

Rasime Öznur Halıc1: https://orcid.org/0000-0003-4072-6757

Arzu Kayın: https://orcid.org/0000-0002-7539-7220

Metin Coban: https://orcid.org/0000-0002-5604-3910
Seyma Trabzon: https://orcid.org/0000-0001-9030-7804 Merve Köseoğlu: https://orcid.org/0000-0001-9110-9586 Selma Altındiş: https://orcid.org/0000-0003-2805-5516

\author{
Yazışma Adresi / Correspondence: \\ Rasime Öznur Halıcı \\ Sakarya Ağız ve Diş Sağlığı Hastanesi \\ T: +90505 4528520 E-mail: rasimeoznur@gmail.com
}

Geliș Tarihi / Received : 03-06-2019 Kabul Tarihi / Accepted : 18-07-2019 Yayın Tarihi / Online Published: 29-08-2019

Kaya G., Halıcı Ö.R., Kayın A., Çoban M., Trabzon Ş., Köseoğlu M., Altındiş S.,

İlköğretimde Okuyan Öğrencilerin Ailelerinin Diş Sağlığına Yönelik Bilgi Düzeylerinin Değerlendirilmesi: Pilot Çalışma

J Biotechnol and Strategic Health Res. 2019;3(2):79-84 DOİ:10.34084/bshr.573560

$\ddot{0} z$

Amaç Çocuğun diş sağlığı davranışlarının geliştirilmesinde diş hekimine olduğu kadar aileye de görevler düşmektedir. Çalışmada ilköğretim okullarında (İÖO) eğitim gören öğrencilerin velilerinin diș sağlığına yönelik bilgi düzeylerinin değerlendirilmesi amaçlanmıștır.

Gereç ve Tanımlayıcı olarak planlanan çalışma, Nisan'2014 tarihinde Sakarya Arifiye ilçesine bağlı ilkokullarda okuyan öğrencilerin velileri ile yapıldı. Literatürden yararlanılarak oluşturulan 22 soruluk anket formu, çalışmaya katılmayı kabul eden toplam 288 veli tarafından doldurulmuş, veriler SPSS 21 programında irdelenmiștir.

Bulgular Katılımcıların 268’i (\%93.0) kadın olup yaş ortalaması $35.6 \pm 8.5$ (18-79) idi. Görüşülen velilerin 178’i ilköğretim, 60’ ortaöğretim, 12’si önlisans, 38’i lisans mezunuydu. Diş firçalama șekli sorulduğunda; 35’i sağa-sola, 68'i yukarı-aşağı firçalama, 180 'i sağ sol, yukarı aşağı ve dairesel firçalama yöntemlerini sıralarken 5’i nasıl firçaladığını bilmiyordu. Diș bakımı için velilerden 215'i diș fırçası, 33'ü kürdan, 26'sı diș ipi, 5'i diğer yöntemler kullanırken 9'u hiç diș bakım materyali kullanmamaktaydı. Velilerin 7’si kendi diş eti sağlığını çok kötü, 37’si kötü, 121'i orta, 78'i iyi, 16’s sçok iyi olarak tanımlarken; 29’unun kendi diş eti sağlığı hakkında fikri yoktu. Diş eti kanamasının nedenine 108'i bilmiyorum cevabı verirken; 80'i diş eti çekilmesi, 87'si diş eti iltihaplanması, 13'ü sağlıklı diş etine bağlı olduğunu ifade etti. Diş eti plağını 103'ü bilmezken; 109 'u dis yüzeyindeki tașlar, 51'i diș yüzeyindeki tabaka, 25’i dis yüzeyindeki renklenme olarak belirtti. “Dis hekimi kontrolü neden önemlidir?” sorusuna 57’si erken teșhis, 145’i diş sağlığının korunması, 66’sı genel sağlığın korunması, 9’u ucuz ve kolay tedavi nedeni olarak yanıtlanmıştır.

Sonuç Çalışmamızda, ailelerin diş eti hastalıkları ve diș plağı konularında yeterli bilgiye sahip olmadıkları görüldü. Oral hijyenin bilinmesi, sağlanması ve sürdürülmesi amacıyla erişkin eğitim planlamaları ile bilgi düzeylerinin artması gerekliliği düşünülmüştür.

Anahtar Ağızdişs sağlığı, Ağız hijyeni, diș tarama programı, ilköğretim aileleri, bilgi düzeyi.

Kelimeler

Abstract

Objective

Materials and

Method

Results

In the development of the child's dental health behaviors, the family has duties as much as the dentist. The aim of this study was to evaluate the knowledge level of the parents of the students who are educated in primary schools (Elementary Schools) about dental health

The descriptive study was carried out with the parents of the students in primary schools of Arifiye district of Sakarya in April 2014. A questionnaire form consisting of 22 questions was prepared by 288 parents who accepted to participate in the study and the data were analyzed in SPSS 21 program.

$268(93.0 \%)$ of the participants were female and the mean age was $35.6 \pm 8.5$ (18-79) years. Of the parents interviewed, 178 were primary 60 were secondary, 12 were assaciate degree and 38 were undergraduate. When asked how to brush teeth; 35 had left-right, 68 up-down brushing, 180 left-right, up-down and circular brushing methods did not know how to brush the 5. 215 of the parents used toothbrush, 33 toothpicks, 26 dental floss, 5 of them used other methods, 9 of them did not use any dental care materials. The participants stated the their gum health as; 7 of them had very bad, 37 were poor, 121 were moderate, 78 were good, 16 were very good. 29 had no idea about their gum health. 108 do not know the cause of bleeding gums; 80 had gingival recessions, 87 had gingivitis and 13 were due to healthy gums. 103 did not know the gingival plaque; 109 of the stones on the surface of the teeth, 51 of the surface of the tooth layer, 25 of the surface of the tooth as coloration. 57 early diagnosis, 145 dental health protection, 66 general health protection, 9 and as the reason for easy and economically advantegous treatment.

Conclusion In our study, it was seen that families do not have enough information about periodontal diseases and dental plaque. In order to know, reach and maintain oral hygiene, it is considered that adult education planning and knowledge levels should be increased. 


\section{GİRIŞ}

Ağı ve diş sağllğı sorunları özellikle diş çürükleri günümüzde dünyanın birçok ülkesinde başta gelen halk sağlığı problemlerindendir. ${ }^{1-4,14}$ Ağız ve diş sağglı̆̆ı, yaşam kalitesinin belirleyicisi olup genel sağlığın önemli bir parçasıdır.--6,14-17 Gelişmiş ülkelerde diş çürüğü yaygınlığında azalma olmasına rağmen, gelişmekte olan ülkelerde artış görülmektedir. Gerek gelişmiş, gerek gelişmekte olan ülkelerde diş çürügü prevelansı ülkeden ülkeye, ülke içinde de bölgeden bölgeye değişiklik gösterdiği bildirilmiştir., ${ }^{4,715-17}$ Diş çürümesine pek çok etken neden olmaktadır. Aşırı sıcak, soğuk yeme ve içme alışkanlı̆̆ı, sert kabuklu yiyeceklerin dişle kırılması, bol miktarda şekerli yiyeceklerin tüketilmesi, kalsiyum, flor ve vitamin D’nin yetersiz tüketilmesi ve lokal enfeksiyonlar bu etkenlerin başında gelmektedir., ${ }^{3,8}$ Birçok hastalıkta olduğu gibi ağız sağlığında hijyenin önemi büyüktür. Ağız hijyenine dikkat edilmemesi ve sorunlu olan dişlerin tedavi edilmemesi diş plaklarının kaybolmasına ve dişlerin daha hızlı çürümesine sebep olmaktadır. Ağız boşluğunda yara ve iltihaplar oluşmakta, diş eti çekilmesi ve diş çürüğü gelişebilmektedir. Dişte ağrı ya da ağıda ileri düzey bir hastalık oluştuktan sonra dişin kurtarılması ve hastalığın tedavisi güçleşmektedir. Çürüyen diş, ağız ve diş eti hastalıklarına, septisemi, aritmi gibi pek çok organı etkileyebilecek hastalıklara yol açabilmektedir. ${ }^{3,16}$

Çocuklarda koruyucu diş hekimliği, mevcut dişleri çürük oluşmadan korumaya yönelik hizmetleri içerir. Çocuklarda diş tedavi uygulamalarının başarı ile sonuçlanmasının yanı sıra ağı hijyeninin sağlanması ve sürdürülebilmesi, çocukta davranış değişikliğinin geliştirilmesi önemlidir. Çocuklarda, ağız sağlığının geliştirilmesi anlayışı, yaşamın ileri dönemlerine taşınacak olan diş firçalama alışkanlığ1, diyet kontrolü, sigara içmeme gibi genel sağlıkla ilgili alışkanlıkların çoğu çocukluk döneminde edinildiği düşüncesinden doğmuştur. Çocuklar bu dönemde, ailesinin, öğretmenlerinin ya da hekimlerin davranış ve sözlerinden etkilenmekte ve onları taklit etmektedir. Diş fırçalama, diş ipi kullanma, beslenme alışkanlıklarını düzenleme, flor uygulamaları ve rutin diş hekimi kontrollerin aksatılmadan yerine getirilmesi ebeveynler, çocuk ve diş hekiminin işbirliğiyle gerçekleştirilirse, çocuğa ömür boyu sürecek iyi bir ağız-diş sağlığı kazandırılabilir. ${ }^{2,67,714,15}$

$\mathrm{Bu}$ çalışmada; ilköğretim okullarında öğretim gören öğrenci velilerinin diş sağlığı ile ilgili bilgi düzeylerinin değerlendirilmesi ve sonraki eğitimlere ışık tutması amaçlandi.

\section{GEREÇ ve YÖNTEM}

Araştırma tanımlayıcı tip çalışma olup 2012-2014 yıllarında Sakarya ili Arifiye ilçesinde bulunan İlköğretim Okullarında okuyan öğrencilere ağı diş sağlığı taraması ve eğitimleri yapılmış, eğitimler sonrasında çocuklarda ağız bakımı ve hijyeni ile ilgili davranış değişikliğinin kalıcı olmaması; ailelerin çocuklarını malzeme ve alışkanlık anlamında yeterince desteklemediklerini ve konu ile ilgili yeterli bilgiye sahip olmadıklarını düşündürdü. Öğrenci velilerine anket yapılarak bilgi düzeylerinin ölçülmesi amaçlandi.

\section{a-Araştırmanın yapıldığı yer ve zaman}

Çalışma 01 - 30 Nisan 2014 tarihlerinde Sakarya Arifiye ilçesinde bulunan Açmalar İlköğretim Okulu (İÖO), Arifiye İÖO, Adliye İÖO, Așağı Kirazca İÖO, Bekir Sttkı İÖO, Hacıköy İÖO, Hanlı İÖO, Kazım Karabekir İÖO, Kemaliye İÖO, Milli Egemelik İÖO, Nevaiye İÖO okullarında yürütüldü. Araştırmada örneklem seçimine gidilmemiş, araştırmaya katılmayı kabul eden İÖO eğitim gören çalışmaya kabul eden 288 velinin katılımı ile yapılmıştır.

\section{b-Anket Formu}

Araştırmacılar tarafından literatürden destek alınarak oluşturulan anket formu, sosyo demografik verilere ilişkin bilgileri içeren 3 soru ve ağız ve diş sağlığına ilişkin bilgileri içeren 19 soru olmak üzere toplam 22 sorudan oluşmaktadır. 


\section{c-Verilerin Toplanması:}

Çalışmanın verileri 01 - 30 Nisan 2014 tarihleri arasında toplandı. Veriler araştırmacı tarafından okul taraması esnasında öğrenci velilerine bilgi verildikten ve çalışmaya katılmayı kabul ettikten sonra ailelere anket formu verildi ve doldurmaları istendi. Anket formunu cevaplamaları için ailelere yaklaşık 20-25 dakika süre tanınmıştır.

\section{d-Verilerin Değerlendirilmesi:}

Veriler bilgisayarda SPSS 21 programında analiz edildi ve $\mathrm{p}<0.05$ anlamlı kabul edildi. Verilerin değerlendirilmesinde; kategorik değişkenler için sayı ve yüzde, sayısal değişkenler için ortalama, standart sapma, minimum ve maksimum değerler kullanılmıştır.

\section{e-Araştırma İzinleri}

Çalışma planlama aşamasında gerekli kurum izinleri alınmıştır. Çalışmaya katılmayı kabul eden aileler çalışma kapsamına alındı.

\section{BULGULAR}

Ailelerin demografik verilerine ait bulgular Tablo1'de ve ağı ve diş sağlı̆̆ hijyeni uygulamalarına ilişkin bilgiler ise

Tablo 2'de gösterilmiştir.

\begin{tabular}{|l|c|c|}
\hline \multicolumn{2}{|c|}{ Tablo-1: Ailelerin demografik verilerine ilişkin bulgular } \\
\hline \multirow{3}{*}{ Cinsiyet } & Özellikler & $\mathbf{n}(\%)$ \\
\hline & Kadın & $268(93,1)$ \\
\cline { 2 - 3 } & Erkek & $20(6,9)$ \\
\hline \multirow{4}{*}{ Eğitim Durumu } & Yaş Ortalaması & $35,6 \pm 8,5(18-79)$ \\
\cline { 2 - 3 } & İlköğretim & $178(61,8)$ \\
\cline { 2 - 3 } & Ortaöğretim & $60(20,8)$ \\
\cline { 2 - 3 } & Ön lisans & $12(4,1)$ \\
\cline { 2 - 3 } & Lisans & $38(13,1)$ \\
\hline
\end{tabular}

Tablo-2: Ailelerin ağız ve diş sağlığı hijyeni uygulamalarına iliş̧in bilgiler

\begin{tabular}{|c|c|c|}
\hline \multicolumn{2}{|c|}{ Ağız ve Diş Sağlığına İlişkin Uygulamalar } & n (\%) \\
\hline \multirow{3}{*}{ Diş Furçalama Şekli } & $\begin{array}{l}\text { Sağa-sola fırçala- } \\
\text { ma }\end{array}$ & $35(12,2)$ \\
\hline & $\begin{array}{l}\text { Yukar1-aşağı } \\
\text { fırçalama }\end{array}$ & $68(23,6)$ \\
\hline & $\begin{array}{l}\text { Sağ-sol ve yukarı } \\
\text { aşağı dairesel } \\
\text { furçalama } \\
\end{array}$ & $180(62,5)$ \\
\hline \multirow{7}{*}{ Diş Fırçalama Sıklığı } & Bilmiyorum & $5(1,7)$ \\
\hline & Günde 3 kez & $23(8)$ \\
\hline & Günde 2 kez & $105(36,5)$ \\
\hline & Günde $1 \mathrm{kez}$ & $107(37,2)$ \\
\hline & Haftada bir & $22(7,6)$ \\
\hline & Ara sira & $21(7,3)$ \\
\hline & Hiç furçalamam & $10(3,5)$ \\
\hline \multirow{3}{*}{ Diş Fırçalama Zamanı } & Yemeklerden önce & $69(24)$ \\
\hline & Yemeklerden sonra & $77(26,7)$ \\
\hline & $\begin{array}{c}\text { Yemeklerden önce } \\
\text { ve sonra }\end{array}$ & $142(49,3)$ \\
\hline \multirow{4}{*}{ Diş Furçalama Süresi } & $1 \mathrm{dk} \mathrm{az}$ & $44(15,3)$ \\
\hline & $1-3 \mathrm{dk}$ & $173(60,1)$ \\
\hline & $3 \mathrm{dk}$ fazla & $41(14,2)$ \\
\hline & Kanayana kadar & $7(2,4)$ \\
\hline \multirow{4}{*}{ Diş Bakım Materyali } & Diş fırçası & $215(74,7)$ \\
\hline & Kürdan & $33(11,5)$ \\
\hline & Diş ipi & $26(9)$ \\
\hline & Diğer materyaller & $9(3,1)$ \\
\hline \multirow{4}{*}{$\begin{array}{l}\text { Diş Fırçası Değiştirme } \\
\text { Süresi }\end{array}$} & 3 ayda bir & $184(63,9)$ \\
\hline & 6 ayda bir & $71(24,7)$ \\
\hline & Yilda bir & $30(10,4)$ \\
\hline & 2 yılda bir & $3(1)$ \\
\hline
\end{tabular}

Ailelerin Diş Hekimi Kontrolünün Önemi Sorusuna Verdikleri Cevaplar (n)

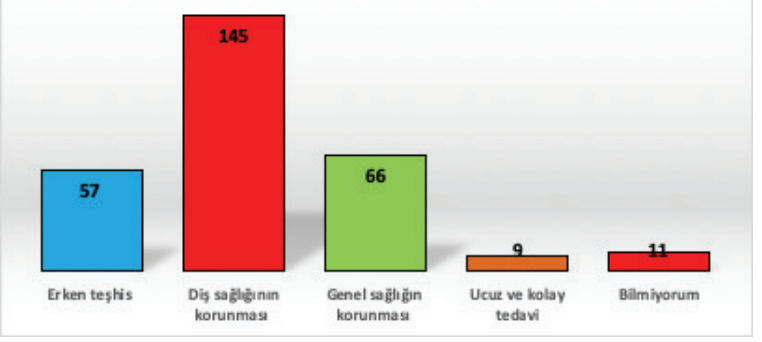

Şekil-1: Ailelerin Diş Hekimi Kontrolünün Önemi Sorusuna Verdikleri Cevaplar 
Ailelerin ortalama $\% 2.7 \pm 2.1$ çürük dişi, $\% 3.2 \pm 2.4$ dolgulu dişi vardı ve $\% 4 \pm 4.6$ 'sı ise diş çekimi yaptırmıştı. Diş fırçalama şekli sorulduğunda; 35'i sağa-sola, 68'i yukarı-aşağı fırçalama, 180'i sağ sol, yukarı aşağı ve dairesel firçalama yöntemlerini sıralarken 5'i nasıl fırçaladığını bilmiyordu. Diş bakımı için velilerden 215'i diş fırçası, 33'ü kürdan, 26's diş ipi, 5'i diğer yöntemler kullanırken 9'u hiç diş bakım materyali kullanmamaktaydı. Veliler kendi diş eti sağlığını 7 (\%2.4)'si çok kötü, 37 (\%12.8)'i kötü, 121 (\%42)'si orta, 78 (\%27.1)'i iyi, 16 (\%5.6)'si çok iyi olarak tanımlarken; 29 (\%10.1)'i diş eti sağlığını bilemediğini belirtmiştir. Diş eti kanamasının nedenini velilerin 108'i (\%37.5) bilmiyorum cevabı verirken; 80’i (\%27.8) diş eti çekilmesi, 87'si (\%30.2) diş eti iltihaplanması ve 13’ü de (\%4.5) sağlıklı diş etine bağlı olduğunu ifade etmiştir. Diş eti plağını 103'ü (\%35.8) bilmediğni belirtirken; 109'u (37.8) diş yüzeyindeki taşlar, 51’i (\%17.7) diş yüzeyindeki tabaka, 25’i (8.7) diş yüzeyindeki renklenme olarak belirtmiştir. 141'i (\%49) diş ağrıs1, 56’sı (\%19.4) dolgu düşmesi, 32'si (\%11.1) protez yaptırmak için diş hekimini ziyaret ederken; 59'u (\%20.5) diş hekimi ziyaretine hiç gitmediğini belirtmiştir. Ailelerin 214 'ü (\%74.3) kendi çürüklerin tedavi edilmesi gerektiğini ifade ederken; 74’ü (\%25.6) kendi diş çürüklerinin tedavi gerektirecek durumda olmadığını belirtmişlerdir. "Diş hekimi kontrolü neden önemlidir?” sorusuna verilen yanıtlar Şekill'de sunulmuştur. "Süt dişleri ne zaman dökülür?” sorusuna; 26'sı (\%9) 3 yaş, 236'sı (\%81.9) 6 yaş, 16’sı (\%5.6) 10 yaş, 4’ü (\%1.4) 12 yaş ve 6’sı (\%2.1) bilmiyorum cevabını vermiştir. Kalıcı dişler ne zaman çıkar sorusuna; 35’i (12.2)3 yaş, 159'u (\%55.2) 6 yaş, 52'si (\%18.1) 10 yaş, 37’si (\%12.8) 12 yaş, 5’i (\%1.7) bilmiyorum cevabını vermiştir. Son 1 yll içinde velilerin 84'ü (\%29.2) 1 kez, 47’si (\%16.3)

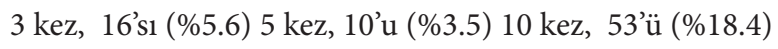
sürekli diş problemi yaşarken; 78'si (\%27) hiç diş problemi yaşamadığını belirtmiştir.

\section{TARTIŞMA:}

Halk sağlı̆̆ını ilgilendiren en önemli problemlerden olan diş çürükleri gelişmiş ülkelerde okul çocuklarının yaklaşık \%60-90'ını etkilemektedir.' Toplum ağız ve diş sağlı̆̆ının korunmasında, çocukların ve onların eğitiminde rol oynayan ailelerinin eğitimi önem arz etmektedir. ${ }^{10}$ Ayrıca, ailelerin ağız diş sağlığı alışkanlıklarının, ergenlik çağına kadar olan çocuklarının bu konudaki davranışlarını etkilediği, örneğin velilerin diş fırçalama gibi olumlu davranışlarının çocuklarına model olduğu bildirilmiştir. ${ }^{11}$

Özyürek ve ark. ${ }^{12}$ çalışmalarında, annelerin \%19.57’sinin süt dişlerinin dökülme zamanını bilmediğini belirtmişlerdir. Çalışmamızda, "Süt dişleri ne zaman dökülür?” sorusuna; \%9'u 3 yaş, \%81.9'u 6 yaş, \%5.6'sı 10 yaş, \%1.4'ü 12 yaş ve \%2.1'i bilmiyorum cevabını vermiştir. Kalıcı dişler ne zaman çıkar sorusuna; \%12.2'si 3 yaş, \%55.2'si 6 yaş, \%18.1'i 10 yaş, \%12.8'i 12 yaş, \%1.7'si ise bilmiyorum cevabını vermiştir.

Özyürek ve ark. ${ }^{12}$ çalışmalarında, annelerin \%13.04'ünün diş eti kanamasının nedenini, \%89.13'ünün diş plağının ne olduğunu bilmediklerini belirtmişlerdir. Çalışmamızda, velilerin \%37.5'idiş eti kanamasının nedenini bilmediğini bildirirken; \%27.8'i diş eti çekilmesi, \%30.2'si diş eti iltihaplanması ve \%4.5'i de sağlıklı diş etine bağlı olduğunu ifade etmiştir. Çalışmamızda ailelerin \%35.8'i diş plağının ne olduğunu bilmezken; \%37.8’ diş yüzeyindeki taşlar, 51'i diş yüzeyindeki tabaka, 25’i diş yüzeyindeki renklenme olarak belirtmiştir.

Özyürek ve ark.nın ${ }^{12}$ çalışmasının sonucuna göre, annelerin \%25’inin dişlerin yemeklerden sonra, \%53.26’sının sabah akşam fırçalanması gerektiğini belirtmektedir. Diş fırçalama sıklığı ile ilgili olarak annelerin \%30.43’ü günde iki kez, annelerin \%65'i günde üç kez dişlerin fırçalanması gerektiğini düşünmektedir. Çalışmamızda, ailelerin diş fırçalama sıklığı ile ilgili olarak büyük bir çoğunluğunun (\%37.2) günde $1 \mathrm{kez}, \% 36.5$ günde $2 \mathrm{kez}$ firçaladı̆̆ 1 belirlenmiştir. Ayrıca velilerin büyük bir çoğunluğu (\%49.3) yemeklerden önce/ sonra, sağ-sol ve yukarı aşağı dairesel firçalama hareketleriyle (\%62.5), 2-3 dk süreyle (\%60.1) dişlerini fırçaladıklarını belirtmişlerdir dişlerini fırçaladıklarını belirtmişlerdir. 
Özyürek ve ark.nın ${ }^{12}$ çalışmasının sonucuna göre, diş hekimine gitme sıklı̆ğ ile ilgili olarak çocukların \%50’si bir problem olduğunda, annelerin \%20.65'i üç ayda bir ve \%53.26'sı altı ayda bir diş hekimine gidilmesi gerektiğini belirtmişlerdir. Çalışmamızda, ailelerin \%49’u diş ağr1s1, 56'sı dolgu düşmesi, \%11.1'i protez yaptırmak için diş hekimini ziyaret ederken; \%20.5'i diş hekimi ziyaretine hiç gitmediğini belirtmiştir. Ailelerin \%50.3’ü, diş hekimi kontrolünün ağız diş sağlığının korunması için önemli olduğunu belirtmişlerdir. Son 1 yll içinde velilerin \%29.2'si 1 kez, \%16.3'ü $3 \mathrm{kez}, \% 5.6$ ’s1 $5 \mathrm{kez}, \% 3.5$ ’i $10 \mathrm{kez}, \% 18.4$ 'ü sürekli diş problemi yaşarken; \%27’si hiç diş problemi yaşamadığını belirtmiştir.

Çalışmamızda, velilerin \% 2.4'ü kendi diş eti sağlığını çok kötü, \%12.8'i kötü, \%42'si orta, \%27.1'i iyi, \%5.6’sı çok iyi olarak tanımlarken; \%10.1'i diş eti sağlığının ne durumda olduğunu bilmediğini belirtmiştir. Ailelerin ortalama 2.7 \pm 2.1 çürük dişi, $3.2 \pm 2.4$ dolgulu dişi vardı ve $4 \pm 4.6$ 'sı ise diş çekimi yaptırmıştı. Ailelerin \%74.3’ü kendi çürüklerin tedavi edilmesi gerektiğini ifade ederken, \%25.6’s kendi diş çürüklerinin tedavi gerektirecek durumda olmadığını belirtmişlerdir. Bu durum, velilerin ağız diş sağlığı bakım hizmetleri gereksinimlerinin yüksek düzeyde olduğunu göstermiştir.

Özmeriç ve ark. ${ }^{13}$ yetişkin Türk popülasyonunda \%6.33’ünün diş ipi, \%10.3’ ünün kürdan kullandığını belirtmişlerdir. Çalışmamızda ailelerin \%74.7’si diş bakım materyali olarak diş fırçası, \%11.5’i kürdan, \%9’u diş ipi, \%3.1'i diğer materyalleri kullandıklarını belirtmişlerdir. Ailelerin büyük bir çoğunluğu (\%63.9) diş fırçasını 3 ayda bir değiştirdiğini belirtmişlerdir.

Sonuç: Çalışmamızda, ailelerin diş eti hastalıkları, diş eti plağı, kalıcı dişlerin çıkma süresi konularında yeterli bilgiye sahip olmadığı görülmüştür. Oral hijyenin korunması ve sürdürülmesi amacı ile ailelerin eğitim süreçlerine dahil edilmesi ve konu ile ilgili eğitimlerin verilmesi ile ailelerin bilgi düzeyinin arttırılması gerektiği kanısı oluşmuştur. 
Journal of BSHR 2019;3(2):79-84

\section{Kaynaklar}

1. Çalışkan D., Yaşar F., Tunçbilek A. A.Ü.T.F. 9-10 Sömestr Öğrencilerinin Ağız ve Diş Sağ̆lğı Konusunda Bilgi Düzeyleri, Ankara Üniversitesi Tip Fakültesi Mecmuası, 2002; 55(2):137142

2. Altun C., Güven G., Başak F., Akbulut E. Altt-onbir yaş grubu çocukların ağız-diş sağlı̆̆ yönünden değerlendirilmesi, Gülhane Tip Dergisi 2005; 47: 114-118

3. Ayrancı Ü. Bir grup ilkokul öğrencisinde diş çürüğü saptama araștırması, sted 2005; 14(3): 50-54

4. Erdoğan A., Bozkurt Aİ., Ergin A.i Topaloğlu S., Aydın A., Arslan A., Avcı A., Kurtcephe B., Er F., Çevik İ., Karagöz K., Kahyaoğlu M. Pamukkale Úniversitesi Tip Fakültesi öğrencilerinde ağız-diș sağlğı̆ıın değerlendirilmesi, Pamukkale Tip Dergisi Pamukkale Medical Journal, 2015: 1-9 doi: 10.5505/ptd.2015.09326.

5. Keskin S.,Sarıü̈z B., Patoğlu D., Özdemir M., Topbaş C., Uçar Y. Çukurova Bölgesinde gezici ağız ve diş săğlğı hizmetine duyulan ihtiyacın değerlendirilmesi, GÜ Diş Hekimliği Fakültesi Dergisi 2012; 29(1): 25-32

6. Özbek CD., Eser D., Berktaş-Kayhan K., Ünür M. Okul Çağındaki Çocuklar ile Velilerinin Diş Firçalama Alışkanlıklarının Karş̧laştırılmasıl, J IstanbulUnıvFacDent 2015;49(1):3340. http://dx.doi.org/10.17096/jiufd.

7. Güler C., Eltaş A., Güneș D., Görgen VA., Ersöz M. Malatya İlindeki 7-14 Yaș Arası Çocukların Ağız-DişS Sağlığının Değerlendirilmesi, İnönü Üniversitesi Sağlık Bilimleri Dergisi 2012; 2: 19-24.

8. Al-ansari J.,Honkala E., Honkala S. Oral healthknowledge and behavioramongmalehealthsciencescollagestudents in Kuwait, BMC Oral Health 2003; 3: 2 http://www.biomedcentral. com/1472-6831/3/2
9. WHO. Health 21, The HealthforAllPolicy Framework for the WHO EuropeanRegion. EuropeanHealthforAll Series, No 6, 1999.

10. Boran Z. 11-12 Yaş çocuklarında ağız ve diş sağlğ̆ı eğitiminin etkinliğinin değerlendirilmesi, Yayınlanmamış bitirme tezi, İzmir: Ege Üniversitesi Diş Hekimliği Fakültesi, 2009.

11. Astrom NA, Jakobse R. The effect of parentaldentalhealthbehavior on that of theiradolescentoffspring. ActaOdontologica Scandinavica, 1996; 54, 235-241.

12. Özyürek A, Cinar M, Yavuz N, Bektas M, Cetin A. İlkokul Öğrencileri ve Annelerinin Ağız ve Diş Sağhlğı Konusundaki Bilgi ve Uygulamaları Arasındaki İlişkinin İncelenmesi. Sakarya Üniversitesi Eğitim Fakültesi Dergisi, 2015; 30: 34-48.

13. Özmeriç N, Göfteci B, Kurtiş B, Bal B. Arayüz bakımı ve periodontal sağlı. G.Ü. Dişhek Fak Der 1994; 11: 33-38,

14. Salah N. Comparison of oral health in children aged 5-6 years in the Czech Republic and Yemen, Cent Eur J Public Health. 2018; Dec;26(4):305-309. doi: 10.21101/cejph.a4893.

15. Pan N, Cai L, Guan H, Jin Y. Oral health knowledge, behaviors and parental practices among rural-urban migrant children in Guangzhou: a follow-up study, BMC Oral Health. 2017; Jun 7;17(1):97. doi: 10.1186/s12903-017-0385-2.

16. Marshman Z, Ahern SM, McEachan RRC, Rogers HJ, Gray-Burrows KA, Day Pf. Parents' Experiences of Toothbrushing with Children: A Qualitative Study, JDR Clin Trans Res. 2016 Jul 2016;1(2):122-130. doi: 10.1177/2380084416647727. Epub 2016 Apr 26.

17. Wilson A, Brega AG, Batliner TS, Henderson W, Campagna EJ, Fehringer K, Gallegos J, Daniels D, Albino J. Assessment of parental oral health knowledge and behaviors among American Indians of a Northern Plains tribe, J Public Health Dent. 2014 Spring;74(2):159-67. doi: 10.1111/jphd.12040. Epub 2013 Oct 9. 